BMJ Open Sport \& Exercise Medicine

\title{
Tele-Active Rehabilitation for adolescents with concussion: a feasibility study
}

\author{
Josh Shore (D) ,' Michael G Hutchison (D) ,2 Emily Nalder (D) , ${ }^{1,3}$ Nick Reed (D) , \\ Anne Hunt (D) ${ }^{1,3}$
}

\begin{abstract}
To cite: Shore J, Hutchison MG, Nalder E, et al. TeleActive Rehabilitation for adolescents with concussion: a feasibility study. BMJ Open Sport \& Exercise Medicine 2022;8:e001277. doi:10.1136/ bmjsem-2021-001277
\end{abstract}

- Additional supplemental material is published online only. To view, please visit the journal online (http://dx.doi. org/10.1136/bmjsem-2021001277).

Accepted 11 February 2022

\section{(c) Author(s) (or their} employer(s)) 2022. Re-use permitted under CC BY-NC. No commercial re-use. See rights and permissions. Published by BMJ.

${ }^{1}$ Rehabilitation Sciences Institute, University of Toronto, Toronto, Ontario, Canada ${ }^{2}$ Faculty of Kinesiology and Physical Education, University of Toronto, Toronto, Ontario, Canada

${ }^{3}$ Department of Occupational Science and Occupational Therapy, University of Toronto, Toronto, Ontario, Canada

Correspondence to Dr Anne Hunt; anne.hunt@utoronto.ca

\section{ABSTRACT}

Objectives Active rehabilitation involving subsymptom threshold exercise and education/support promotes recovery among adolescents with concussion, but is typically delivered in-person, which limits accessibility. This study explored the feasibility of a remotely delivered TeleActive Rehabilitation (Tele-AR) intervention for adolescents with concussion.

Methods A precase-postcase series design was used. Three adolescents (ages 14-17 years) experiencing postconcussion symptoms $\geq 2$ weeks postinjury participated with a parent. The Tele-AR intervention was a 6-week programme supervised by a rehabilitation clinician through weekly videoconferencing appointments and included (1) aerobic exercise, (2) coordination drills and (3) comprehensive education and support. Feasibility indicators included rates of recruitment, retention, adherence, as well as adolescent and parent ratings of technology usability using an adapted Telehealth Usability Questionnaire and satisfaction using the Client Satisfaction Questionnaire-8. Prechanges to postchanges in postconcussion symptoms, illness perceptions, and occupational performance and satisfaction were also assessed.

Results Rates of recruitment $(n=3 / 4)$ and retention $(n=3 / 3)$ achieved success criteria. Adherence was high among all participants (77\%-100\%), and there were no adverse events. Participant ratings of technology usability and satisfaction approached $90 \%$. All participants reported improvements in postconcussion symptoms and illness perception. Clinically significant positive changes were also observed in occupational performance and satisfaction. Conclusions The Tele-AR intervention appears feasible in a small group of adolescents with concussion, and positive changes were observed in postconcussion symptoms, illness perception and occupational performance. Further study is warranted to evaluate the efficacy of this approach, which may enable access to care that supports recovery in adolescents with concussion.

\section{INTRODUCTION}

Concussion is a significant public health concern among youth. Compared with children and adults, adolescents (ages 13-18 years) experience prolonged symptom duration following concussion. ${ }^{1}$ Most adolescents

\section{Key messages}

What is already known on this topic

- Active rehabilitation involving supervised subsymptom threshold exercise combined with education and support improves recovery among adolescents with concussion.

- Many families face challenges accessing in-person active rehabilitation services due to geographical, logistical and financial barriers.

\section{What this study adds}

- A remotely delivered Tele-Active Rehabilitation (TeleAR) intervention appears to be a safe and feasible approach for adolescents with concussion.

- Positive changes were observed in postconcussion symptoms, illness perception and occupational performance following the intervention.

How this study might affect research, practice or policy

- Further study is warranted to evaluate the efficacy of the Tele-AR approach, which may help improve access to care that supports recovery in adolescents with concussion.

are expected to achieve symptom resolution within 4 weeks postinjury. ${ }^{12}$ However, a large subset (approximately 30\%) continue to experience persistent physical, cognitive, emotional or sleep-related symptoms beyond 1-month following concussion ${ }^{2}$ and may report disturbances in mood, ${ }^{3}$ activity resumption ${ }^{4}$ and quality of life. ${ }^{5}$

Current guidelines recommend an active approach to concussion management involving gradual activity resumption after an initial 24-48 hours of rest postinjury. ${ }^{6}$ After initial rest, active rehabilitation involving subsymptom threshold exercise promotes recovery. ${ }^{7}$ Active rehabilitation programmes for adolescents involve aerobic exercise, ${ }^{8-16}$ sport coordination drills, ${ }^{9-15}$ balance exercises, $^{11}$ relaxation training $^{9-15}$ and/or concussion education and support. ${ }^{9-15}$ Studies show that active rehabilitation improves symptoms, ${ }^{8-16}$ mood, ${ }^{10}$ occupational performance ${ }^{4}$ 
and quality of life ${ }^{14}$ among adolescents with concussion. Exercises are prescribed by a healthcare provider and performed by adolescents at home multiple (three to seven) times per week. Frequent contact with the clinician ensures that exercises are tailored to adolescents' unique needs, interests and recovery trajectories. This typically involves in-person sessions during which the clinician evaluates progress to guide programme modification. ${ }^{9-15}$

Several barriers limit adolescent engagement in active rehabilitation. Although concussion is more common in rural communities, ${ }^{17}$ active rehabilitation services are often location in urban areas. Families in rural communities face higher healthcare costs for paediatric concussion, ${ }^{18}$ including indirect costs related to transportation and lost productivity. ${ }^{19}$ Adolescents living close to care may also have difficulty attending in-person sessions due to financial or logistical challenges preventing parental accompaniment. Telehealth delivery of a multimodal active rehabilitation programme may help address these barriers and improve access to care but has not been explored among adolescents with concussion.

Our research team developed the Tele-Active Rehabilitation (Tele-AR) intervention, a comprehensive active rehabilitation programme for adolescents with concussion designed to promote return to activity in a remote service delivery format. Feasibility studies are essential in rehabilitation research because interventions are inherently complex due to multiple interacting components, complex target behaviours and the degree of intervention tailoring. ${ }^{2021}$ The purpose of this study was to explore the feasibility of the Tele-AR intervention for adolescents with concussion. Feasibility was evaluated based on

1. Process: rates of recruitment, retention and adherence.

2. Resource: adolescent and parent ratings of technology usability.

3. Science: adverse events, adolescent and parent satisfaction, and preliminary effects on postconcussion symptoms, illness perception and perceived occupational performance

\section{METHODS}

Design

This study was part of a larger mixed-methods project evaluating the feasibility of the Tele-AR intervention. A precase-postcase series design was used.

\section{Participants}

Adolescents were eligible if they met the following inclusion criteria: (1) ages 13-18 years; (2) concussion diagnosis by physician or nurse practitioner; (3) $\geq 2$ weeks postinjury; (4) experiencing $\geq 2$ symptoms from the Postconcussion Symptom Inventory; ${ }^{22}(5)$ ability to read and speak English; (6) demonstrated capacity to consent to the study; (7) access to device and internet capable of videoconferencing; (8) visual analogue rating of current overall symptom burden of $\leq 7 / 10$, where $10=$ feeling very unwell; (9) parent/guardian confirmed ability to walk independently; and (10) parent-reported access to a safe space for exercise. Exclusion criteria included parentreported presence of comorbidities that could prevent safe participation (ie, cardiac condition, severe mental health diagnoses or other neurological disorder) or inability to follow directions during screening. A parent/ guardian was asked to enrol and complete study measures as they observe and/or support their child's participation.

\section{Recruitment}

Participants were recruited via word of mouth and information flyers advertised through community organisations, community practitioners, family health teams and social media. Families who expressed interest were contacted by telephone to determine eligibility.

\section{Intervention}

The Tele-AR intervention is based on the active rehabilitation protocol described by Gagnon et al..$^{9}$ It is a 6-week programme consisting of (1) progressive subsymptom threshold aerobic exercise, (2) sport coordination drills and (3) comprehensive education and support. The Tele-AR protocol was adapted for remote delivery such that the participants were trained by the clinician to exercise independently, rather than under direct supervision by the clinician as in the original protocol. ${ }^{9}$

The intervention was facilitated through seven videoconferencing appointments with a registered kinesiologist. The first appointment (week 0 ) involved informed consent procedures, reviewing history and completing assessments (described further). The second appointment consisted of an interactive education session and collaborative coconstruction of the home programme based on assessment results and participant interests. During the next 6 weeks (weeks 1-6), the participants were asked to perform the home programme 3 days/ week (18 sessions total) and to meet with the kinesiologist once a week. Weekly appointments (approximately $30 \mathrm{~min}$ ) consisted of continued education and support and review of the home programme, including modification as appropriate. Appointments were conducted using Zoom videoconferencing software.

Aerobic exercise consisted of subsymptom threshold activity (walking, jogging or cycling) using an exercise machine, indoor track or outdoor space. Participants began with $10 \mathrm{~min}$ at level $4 / 10$ on the Pictorial Children's Effort Rating Table (PCERT). ${ }^{23}$ If tolerated, aerobic exercise was progressed during weekly appointments following a standardised protocol (see online supplemental material), to a maximum of $30 \mathrm{~min}$ at PCERT level 6. Coordination drills, prescribed for $10 \mathrm{~min}$, included balance, coordination, sport-specific skills or general health exercises that were meaningful based on participant interests and assessments. For example, hockey players may be given stickhandling drills first performed stationary and progressed to include dynamic 
Table 1 A priori feasibility criteria overview

\begin{tabular}{|c|c|c|}
\hline $\begin{array}{l}\text { Feasibility } \\
\text { indicator }\end{array}$ & Success criteria & Measurement \\
\hline Recruitment & $\geq 10 \%$ response rate from eligible participants & $\begin{array}{l}\geq 10 \% \text { of families invited to participate after screening } \\
\text { are successfully enrolled in the study }\end{array}$ \\
\hline Retention & $\geq 90 \%$ retention of participants & $\begin{array}{l}\geq 90 \% \text { of enrolled participants successfully complete } \\
\text { the study, including outcome measures }\end{array}$ \\
\hline Adherence & $\begin{array}{l}100 \% \text { attendance to study appointments* } \\
\geq 85 \% \text { completion of home programme }\end{array}$ & $\begin{array}{l}\text { All participants complete all eight study appointments* } \\
\text { All participants complete at least } 15 / 18 \text { home exercise } \\
\text { sessions }\end{array}$ \\
\hline $\begin{array}{l}\text { Technology } \\
\text { usability }\end{array}$ & $\begin{array}{l}\geq 85 \% \text { technology usability reported by both youth } \\
\text { and parent/guardian }\end{array}$ & $\begin{array}{l}\text { Youth and parents each report mean score of } \geq 72 \text { on } \\
\text { adapted TUQ }\end{array}$ \\
\hline Satisfaction & $\begin{array}{l}\geq 90 \% \text { satisfaction reported by both youth and } \\
\text { parent/guardian }\end{array}$ & $\begin{array}{l}\text { Youth and parents each report mean score of } \geq 29 \text { on } \\
\text { CSQ-8 }\end{array}$ \\
\hline
\end{tabular}

${ }^{*}$ Rescheduling permitted.

CSQ-8, 8-Item Client Satisfaction Questionnaire; TUQ, Telehealth Usability Questionnaire.

movement. Participants were instructed to terminate exercise if symptoms worsened and to rest until symptoms returned to pre-exercise level; time to symptom exacerbation then became the new target duration. Education was based on the evidence-supported Concussion \& You selfmanagement programme, which covers topics including energy management, nutrition/hydration, sleep hygiene and return to activity. ${ }^{24}$

\section{Data collection}

We selected feasibility indicators of process, resource and science. $^{2125}$ Specific criteria for defining feasibility were identified a priori for a subset of the feasibility indicators (table 1).

\section{Process}

\section{Recruitment}

Recruitment was defined as the proportion of participants who enrolled in the study relative to the number of individuals invited to participate after screening. A minimum $10 \%$ response rate has been deemed the minimum feasible response rate for an $\mathrm{RCT}^{26}$

\section{Retention}

Retention was defined as the proportion of enrolled participants who complete the entire study. A $90 \%$ retention target was chosen based on the retention rate in a previous active rehabilitation study facilitated through telephone calls to minimise in-person visits. ${ }^{16}$

\section{Adherence}

Adherence was defined as attendance at appointments and participation in the home programme, which was measured using activity logs that participants were asked to complete daily through REDCap. ${ }^{27}$ Imhoff et al reported $85 \%$ adherence among adolescents prescribed three active rehabilitation sessions per week ${ }^{11}$; therefore, we targeted $85 \%$ home programme completion $(15 / 18$ prescribed sessions).

\section{Resource}

\section{Technology usability}

Adolescent and parent ratings of technology usability were evaluated through postintervention questionnaires (see online supplemental material). Nine questions were chosen from the Telehealth Usability Questionnaire (TUQ) ${ }^{28}$ to assess usability, interaction quality and usefulness. The TUQ has strong content validity and good-to-excellent internal consistency. ${ }^{28}$ Three additional questions were included to assess reliability. As per the TUQ, participants rated their agreement with each question from 1 (complete disagreement) to 7 (complete agreement). Total score was determined as the mean score of all items. An $85 \%$ usability rating was chosen to indicate feasibility.

\section{Science}

\section{Participant characteristics}

Demographic information and relevant medical history were collected during week 0 to characterise the sample and inform intervention tailoring.

\section{Preliminary clinical effects}

Preliminary effects of the Tele-AR intervention were evaluated through changes in postconcussion symptoms, illness perception and perceived occupational performance. Although concussion recovery is often measured through changes in self-reported symptoms, complete functional recovery per international consensus also encompasses return to regular activities. ${ }^{6}$ Psychological factors such as illness perception predict recovery ${ }^{29}$ and may be influenced by access to care.

\section{Postconcussion Symptom Inventory (PCSI)}

The 22-item PCSI (adolescent version) measures the presence and severity of concussion symptoms on a scale of $0-6 .^{22}$ The PCSI has strong internal consistency $(\alpha=0.72-0.93)$, moderate to strong test-retest reliability (intraclass coeffecients, ICCs $=0.62-0.84$ ) and good 
convergent validity $(r=0.8)$. Higher scores on the PCSI indicate greater symptom severity.

\section{Brief IIIness Perception Questionnaire (BIPQ)}

The BIPQ evaluates cognitive and emotional conceptualisation of illness based on eight factors: consequences, timeline, personal control, treatment control, identity, concern, understanding and emotional response. ${ }^{30}$ Items are rated on a 10-point Likert scale from 0 (absence of perception) to 10 (full agreement with perception). A higher overall score indicates more negative perceptions. The BIPQ has strong psychometric properties and has been administered to patients as young as 8 years old with a variety of conditions. ${ }^{30}$ We adapted the BIPQ for concussion by replacing the word 'illness' with 'concussion'.

\section{Canadian Occupational Performance Measure (COPM)}

The COPM is a client-centred measure to evaluate selfperceived occupational performance and satisfaction. ${ }^{31}$ Through a semistructured interview, participants identify their top 5 areas of occupational concern and rate their performance and satisfaction for each issue from 1 to 10 . Ratings are repeated over time to measure change. The COPM has good reliability, validity and responsiveness in rehabilitation settings among adults and youth. ${ }^{31}$ Previously, the COPM detected positive changes in occupational performance among youth participating in active rehabilitation following concussion. ${ }^{5}$

\section{Satisfaction}

The 8-Item Client Satisfaction Questionnaire (CSQ-8) was used to assess adolescent and parent/guardian satisfaction with the intervention. The CSQ- 8 is a valid and reliable measure to assess parent and child satisfaction with healthcare services. ${ }^{32}$ A $90 \%$ satisfaction rating was chosen to indicate feasibility based on the $91 \%$ parentreported satisfaction with active rehabilitation reported by Gauvin-Lepage et al. ${ }^{10}$ Ten additional purposedesigned questions elicited specific feedback regarding intervention components.

\section{Adverse events}

The following adverse events were chosen to evaluate intervention safety:

1. Exercise-induced symptom exacerbation that persisted beyond 24 hours. ${ }^{15}$

2. Termination of participant's exercise programme due to repeated symptom exacerbation in three consecutive exercise sessions. ${ }^{13}$

3. Serious injury resulting from the programme.

Participants were instructed to contact the research team if adverse events occurred. The occurrence of adverse events was also explored during weekly appointments, and participants were prompted to self-report any additional adverse effects.

\section{Procedure}

After obtaining informed consent, the PCSI, COPM and BIPQ were administered preintervention at the first appointment in week 0 and were repeated immediately postintervention in the week 6 appointment. The PCSI was also administered at week 3 to measure interim change. The CSQ-8 and adapted TUQ were sent via email following the final appointment in week 6 . Parents were asked to attend the first appointment to provide informed consent and the final appointment; additional parental involvement in intervention procedures was determined by the family. Participants were offered a gift card and high school volunteer hours as a token of appreciation.

\section{Data analysis}

Participant demographics and history were summarised descriptively. Feasibility indicator results were summarised using frequencies/ratios and were compared against the success criteria (table 1). Descriptive statistics were used to summarise preintervention to postintervention changes on the PCSI, COPM and BIPQ. Changes on the COPM were evaluated in relation to the clinically significant change of 2 or more points on performance and satisfaction scores. ${ }^{31}$

\section{Patient and public involvement}

Patients and the public were not involved in the design, conduct, reporting, dissemination plans of this research.

\section{RESULTS}

Sample

The final study sample consisted of three adolescents (ages 14-17 years, $\mathrm{n}=2$ female) who ranged from 5 weeks to 24 weeks postconcussion and continued to experience symptoms at enrolment. One parent participated alongside each adolescent (all mothers). See table 2 for participant characteristics.

\section{Process}

Recruitment

Five families contacted the research team regarding the study. Four participants were screened for eligibility; all met the inclusion criteria and were invited to enrol. One family was unreachable following screening and thus not enrolled. Three participants recruited from four invited represented a $75 \%$ recruitment rate, demonstrating success for the recruitment criterion.

\section{Retention}

All participants (100\%) were retained until completion of all study procedures. The $90 \%$ retention criterion was thus met.

\section{Adherence}

All adolescent participants completed all study appointments. Response rates for the daily activity log surveys were $84 \%, 56 \%$ and $98 \%$ for participant 1 (P1), participant 2 (P2) and participant 3 (P3), respectively. The mean number of exercise sessions completed per week 
Table 2 Participant characteristics

\begin{tabular}{|c|c|c|c|}
\hline & Participant 1 & Participant 2 & Participant 3 \\
\hline Age (years) & 17 & 14 & 14 \\
\hline Gender & Female & Female & Male \\
\hline Number of previous concussions & 0 & 0 & 0 \\
\hline Time since injury (weeks) ${ }^{*}$ & 24 & 5 & 5 \\
\hline Mechanism of injury & Sport & Fall & Sport \\
\hline Relevant preinjury diagnoses & Chronic migraines & $\begin{array}{l}\text { Learning disabilities } \\
\text { ADHD } \\
\text { Mood disorders }\end{array}$ & $\begin{array}{l}\text { Vision disorder } \\
\text { Learning disability } \\
\text { Mood disorder }\end{array}$ \\
\hline Concurrent treatment & $\begin{array}{l}\text { Physiotherapy } \\
\text { Occupational therapy } \\
\text { Chiropractic } \\
\text { Vision therapy } \\
\text { Neurology }\end{array}$ & None & None \\
\hline
\end{tabular}

*Time since injury on initiating intervention.

$\mathrm{ADHD}$, attention deficit hyperactive disorder.

was $3.44(\mathrm{SD}=2.15$, median=4). Of the 18 exercise sessions prescribed, $\mathrm{P} 1$ reported completing 16 sessions; P2 reported completing 14 sessions; and $\mathrm{P} 3$ reported completing 32 sessions. Adherence criteria were thus met for P1 and P3 and approached for P2.

\section{Resource}

Technology usability

Usability was rated above the success criterion of $85 \%$ by P2 and parent (both 94\%) and by P3 and parent (both $98 \%)$. Usability was rated lower by P1 $(73 \%)$ and parent $(80 \%)$ due to technical problems (ie, poor internet connection). All adolescents and parents rated $5 / 7$ or higher in agreement that videoconferencing was appropriate for delivering the intervention, and 5/7 or higher in agreement that telerehabilitation saved them time travelling to concussion specialists.

\section{Science}

\section{Postconcussion symptoms}

All three adolescent participants demonstrated decreases in postconcussion symptoms (PCSI) from preintervention

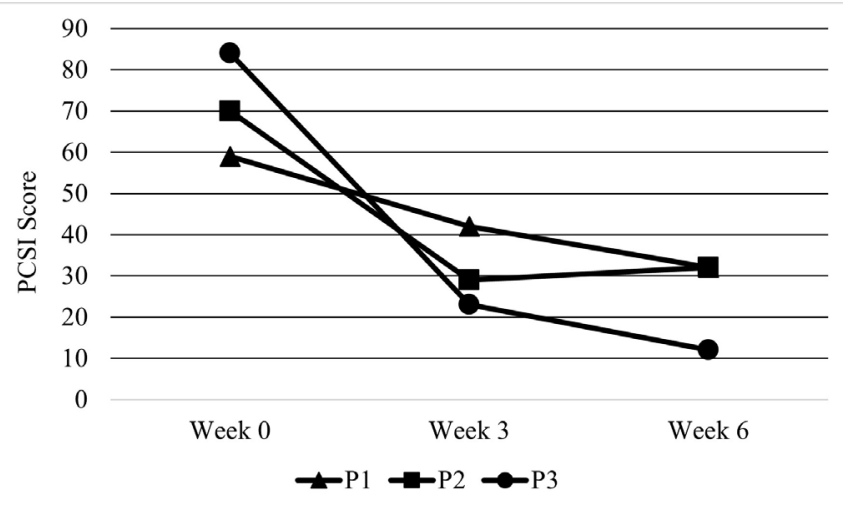

Figure 1 PCSI scores. Note: lower scores indicate lower symptom severity. PCSI, Postconcussion Symptom Inventory to postintervention (figure 1). Symptom reduction was most pronounced from week 0 to week 3 for all participants. P2 had a slightly higher symptom score at week 6 compared with week 3 (32 and 29, respectively), but the symptoms at these time points were similar to those endorsed for the preinjury rating.

IIIness perception

All three adolescent participants showed lower scores on the BIPQ from preintervention to postintervention, indicating more favourable perceptions of their condition (figure 2). P2 and P3 reported almost entirely favourable perceptions at week $6(\mathrm{BIPQ}$ score $=4$ and 2 , respectively), while P1 continued to endorse some negative perceptions (BIPQ score=36).

Occupational performance

COPM scores are shown in table 3. Some details were substituted to protect participant privacy (eg, lacrosse changed to ice hockey). Participants reported a variety of occupational performance issues related to productivity

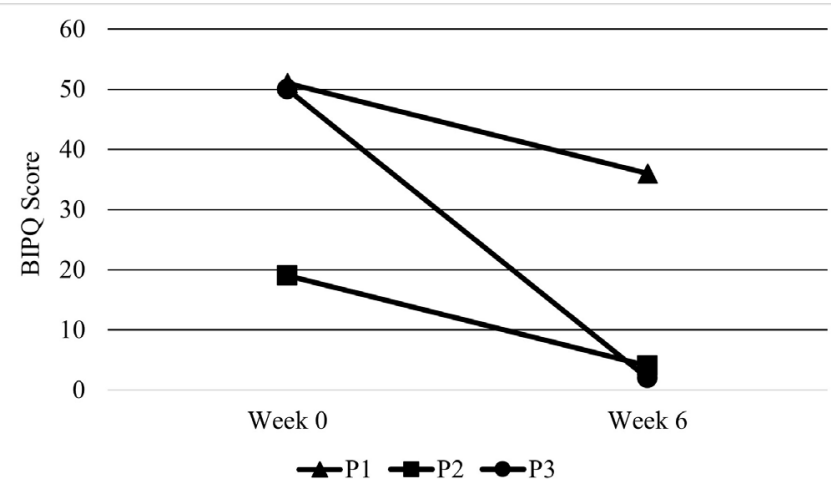

Figure 2 BIPQ scores. Note: lower scores indicate more positive perceptions. BIPQ, Brief Illness Perception Questionnaire. 
Table 3 Performance and satisfaction ratings for self-identified occupational performance issues (Canadian Occupational Performance Measure)

\begin{tabular}{|c|c|c|c|c|}
\hline \multirow[b]{2}{*}{ Occupational performance issues } & \multicolumn{2}{|l|}{ Week 0} & \multicolumn{2}{|l|}{ Week 6} \\
\hline & Performance & Satisfaction & Performance & Satisfaction \\
\hline \multicolumn{5}{|l|}{ Participant 1} \\
\hline Performing exercise (cycling, swimming and running) & 3 & 4 & 5 & 6 \\
\hline Participating in sport (ice hockey and softball) & 1 & 1 & 6 & 7 \\
\hline Completing household chores (laundry and dishes) & 5 & 7 & 6 & 8 \\
\hline Driving a car & 1 & 1 & 5 & 7 \\
\hline Completing schoolwork & 4 & 3 & 8 & 8 \\
\hline Averages & 2.8 & 3.2 & 6 & 7.4 \\
\hline Change scores* & \multicolumn{4}{|c|}{$\begin{array}{l}\text { Change in performance score }=3.2 \\
\text { Change in satisfaction score }=4.2\end{array}$} \\
\hline \multicolumn{5}{|l|}{ Participant 2} \\
\hline Completing schoolwork & 7 & 4 & 8 & 7 \\
\hline Using screens (computer, TV and cellphone) & 9 & 9 & 10 & 10 \\
\hline Reading books & 8 & 6 & 10 & 10 \\
\hline Going to stores & 7 & 4 & 10 & 10 \\
\hline Averages & 7.8 & 5.8 & 9.5 & 9.3 \\
\hline Change scores* & \multicolumn{4}{|c|}{$\begin{array}{l}\text { Change in performance score }=1.8 \\
\text { Change in satisfaction score }=4.5\end{array}$} \\
\hline \multicolumn{5}{|l|}{ Participant 3} \\
\hline Swimming & 5 & 4 & 6 & 5 \\
\hline Completing schoolwork & 5 & 4 & 9 & 10 \\
\hline Leisure cycling & 2 & 2 & 10 & 10 \\
\hline Using screens (computer, TV and cellphone) & 2 & 2 & 8 & 10 \\
\hline Playing electric guitar & 1 & 1 & 9 & 10 \\
\hline Averages & 3 & 2.6 & 8.4 & 9 \\
\hline Change scores* & \multicolumn{4}{|c|}{$\begin{array}{l}\text { Change in performance score }=5.4 \\
\text { Change in satisfaction score }=6.4\end{array}$} \\
\hline
\end{tabular}

Higher score indicates greater performance and satisfaction. Bold indicates clinically significant change (2 or more points) from week 0 to week 6.

${ }^{*}$ Calculated as week 6 average-week 0 average.

and leisure. Clinically significant changes ( $\geq 2$ points) in occupational performance were observed from preintervention to postintervention for P1 and P3. P2 approached a clinically significant change (1.75-point improvement). All participants reported clinically significant changes in satisfaction. Due to the COVID-19 lockdown measures, P3 was unable to access a pool beyond week 2, which limited postintervention ratings for swimming.

\section{Satisfaction}

The $90 \%$ satisfaction criterion was met for P1 (90\%) and the parents of P2 and P3 (both 94\%). Satisfaction ratings from P2 $(88 \%)$ and P3 $(85 \%)$ approached the $90 \%$ target. The parent of P1 reported slightly lower satisfaction $(75 \%)$. All adolescents rated that the programme 'helped a great deal' or 'helped somewhat' to deal more effectively with concussion and indicated that they would 'definitely' recommend the programme to others. P2 and P3 identified education/support as the most helpful aspect of the programme, while P1 chose the aerobic component.

\section{Adverse events}

No adverse events were reported by the participants at any point. Two participants experienced symptom exacerbation during their first or second exercise session that subsided within the 24-hour period and therefore were not considered adverse events.

\section{DISCUSSION}

This study explored the feasibility of a remotely delivered Tele-AR intervention for adolescents with concussion. Results based on a priori indicators suggest that the Tele-AR intervention may be a feasible approach in this population. Participants reported positive changes in postconcussion symptoms, illness perception and occupational performance from preintervention to postintervention. 
Results from this study extend prior research supporting a telehealth approach to exercise for youth with concussion. ${ }^{33}$ The Mobile Subthreshold Exercise Programme intervention used heart rate monitors and weekly video appointments to guide adolescents in adjusting exercise parameters based on their symptoms, which was found to be tolerable and acceptable. ${ }^{33}$ The Tele-AR intervention trains similar self-monitoring skills and provides a structured and supervised exercise programme for those without access to exercise testing or heart rate monitors. High satisfaction ratings and the lack of adverse events reported here suggest that this approach may also be safe and appropriate. Together, these findings highlight the potential for telehealth approaches that support youth to safely monitor and progress postconcussion rehabilitative exercise at home.

Improvements in symptoms and occupational performance reported by our participants are comparable to previous in-person active rehabilitation studies, ${ }^{4-15}$ indicating that the intervention may have similar beneficial effects when delivered remotely. Performance improved across a variety of activities commonly limited by concussion, including sport/exercise, schoolwork and leisure hobbies. ${ }^{4}$ Tailored education and support were essential to ensuring individualisation of the intervention and extending beyond exercise to address activities that were meaningful to each participant. Indeed, two participants identified education/support as the most helpful component, which is consistent with previous work in which youth highlighted energy management strategies as essential to active rehabilitation. ${ }^{34}$ Understanding adolescents' ongoing symptoms and activity limitations is key to tailoring a comprehensive active rehabilitation approach.

Improvements in illness perception further underscore the importance of education/support. Poor understanding of concussion and negative injury perceptions are associated with prolonged recovery. ${ }^{29}$ In this study, all participants endorsed negative perceptions of their injuries at week 0 but showed lower scores (ie, more positive perceptions) after the intervention. While cognitivebehavioural approaches are known to improve illness perception and related behaviours in concussed adolescents, ${ }^{35}$ to our knowledge, this study is the first to suggest that illness perception may be responsive to tailored education and support combined with supervised exercise among adolescents with concussion. The education/ support component, which focused on self-management strategies and active recovery, may have contributed to more positive injury beliefs, facilitating safe activity engagement. Mastery experiences during exercise could have also contributed by increasing perceived competence and autonomy. Further study is needed to explore these relationships.

This study adds to emerging literature regarding telehealth in concussion management. ${ }^{36-38}$ Adoption of telehealth has been slow in concussion research and clinical care, perhaps due to beliefs that screens should be avoided during recovery. However, current evidence indicates that strict avoidance of screen use is not necessary beyond 24-48hours postconcussion. ${ }^{39} 40$ In our study, screen use was apparently tolerated by participants, as ratings of technology usability and satisfaction were high and there were no adverse events. In another study, adolescent and caregiver ratings of therapeutic alliance and satisfaction were similar between concussion visits conducted in-person and via telehealth. ${ }^{37}$ Communication strategies that honour patient autotomy (eg, eliciting perspectives, demonstrating active listening and encouraging questions) can help build rapport in telehealth encounters. ${ }^{37}$ Clinicians providing telehealth services for concussion should also be mindful of individual screen tolerance and schedule appointments appropriately, including breaks as needed.

\section{Considerations and future directions}

This study took place during the COVID-19 pandemic (recruitment May 2020-March 2021) when concussion care-seeking was reduced due to lockdown measures, ${ }^{41}$ which may have impacted recruitment. The small sample size limited interpretation of process outcomes. Nevertheless, results were consistent with previous in-person active rehabilitation literature and provided preliminary evidence to guide the design of future studies. Further study including a larger sample size and control group is necessary to evaluate this approach. Adherence to the home programme should be interpreted cautiously due to mixed response rates to activity log surveys and potential biases from self-reporting. Adherence should be explored further, including the impact of telehealth visits.

\section{CONCLUSIONS}

The Tele-AR intervention appears feasible in a small group of adolescents with concussion, and positive changes were observed in postconcussion symptoms, illness perception and occupational performance. This study is the first step towards evaluation and clinical implementation of Tele-AR, which may enable access to care that supports recovery and return to activity among adolescents with concussion.

Acknowledgements We thank the families who participated in this research and the OAK concussion lab team (University of Toronto). We also acknowledge the contributions of former University of Toronto Master of Professional Kinesiology students Joe Pendleton and Olivia Kitchener.

Contributors JS contributed to the study design, recruited participants, administered the intervention, completed the data collection and analysis, and drafted and revised the manuscript. MGH and EN contributed to the study design, assisted with data analysis and revised the manuscript. NR and AH generated the theoretical basis for the study, contributed to the study design, assisted with recruitment and data analysis, and revised the manuscript. All authors approved the final manuscript. $\mathrm{AH}$ is the guarantor and accepts full responsibility for the work, had access to the data, and controlled the decision to publish.

Funding This research was supported by the Canadian Institutes of Health Research (Frederick Banting and Charles Best Canada Graduate Scholarship Master's); Ontario Graduate Scholarship and the Hilda and William Courtney Clayton Paediatric Fund. 
Competing interests None declared.

Patient and public involvement Patients and/or the public were not involved in the design, conduct, reporting or dissemination plans of this research.

Patient consent for publication Not applicable.

Ethics approval This study involves human participants and was approved by University of Toronto Health Sciences Research Ethics Board (REB) (REB reference number 00039179). Participants gave informed written consent to participate in the study before taking part.

Provenance and peer review Not commissioned; externally peer reviewed

Data availability statement Data are available upon reasonable request.

Open access This is an open access article distributed in accordance with the Creative Commons Attribution Non Commercial (CC BY-NC 4.0) license, which permits others to distribute, remix, adapt, build upon this work non-commercially, and license their derivative works on different terms, provided the original work is properly cited, appropriate credit is given, any changes made indicated, and the use is non-commercial. See: http://creativecommons.org/licenses/by-nc/4.0/.

\section{ORCID iDs}

Josh Shore http://orcid.org/0000-0002-9060-2173

Michael G Hutchison http://orcid.org/0000-0003-1961-5921

Emily Nalder http://orcid.org/0000-0001-9612-9420

Nick Reed http://orcid.org/0000-0001-9360-7888

Anne Hunt http://orcid.org/0000-0002-1933-6503

\section{REFERENCES}

1 Davis GA, Anderson V, Babl FE, et al. What is the difference in concussion management in children as compared with adults? A systematic review. Br J Sports Med 2017;51:949-57.

2 Zemek R, Barrowman N, Freedman SB, et al. Clinical risk score for persistent postconcussion symptoms among children with acute concussion in the ED. JAMA 2016;315:1014-25.

3 Ellis MJ, Ritchie LJ, Koltek M, et al. Psychiatric outcomes after pediatric sports-related concussion. J Neurosurg Pediatr 2015;16:709-18

4 Sang RC, Vawda Y, Greenspoon D, et al. An innovative approach to measuring youth concussion recovery: occupational performance. Br J Occup Ther 2020;83:220-7.

5 Howell DR, Wilson JC, Kirkwood MW, et al. Quality of life and symptom burden 1 month after concussion in children and adolescents. Clin Pediatr 2019;58:42-9.

6 McCrory P, Meeuwisse W, Dvořák J, et al. Consensus statement on concussion in sport-the $5^{\text {th }}$ international conference on concussion in sport held in Berlin, October 2016. Br J Sports Med 2017;51:838-47.

7 Carter KM, Pauhl AN, Christie AD. The role of active rehabilitation in concussion management: a systematic review and meta-analysis. Med Sci Sports Exerc 2021;53:1835-45.

8 Kurowski BG, Hugentobler J, Quatman-Yates C, et al. Aerobic exercise for adolescents with prolonged symptoms after mild traumatic brain injury: an exploratory randomized clinical trial. J Head Trauma Rehabil 2017;32:79-89.

9 Gagnon I, Galli C, Friedman D, et al. Active rehabilitation for children who are slow to recover following sport-related concussion. Brain Inj 2009;23:956-64.

10 Gauvin-Lepage J, Friedman D, Grilli L. Effectiveness of an exercisebased active rehabilitation intervention for youth who are slow to recover after concussion. Clin J Sport Med 2018;30:423-32.

11 Imhoff S, Fait P, Carrier-Toutant F, et al. Efficiency of an active rehabilitation intervention in a slow-to-recover paediatric population following mild traumatic brain injury: a pilot study. J Sports Med 2016;2016:1-11.

12 Dobney DM, Grilli L, Kocilowicz H, et al. Evaluation of an active rehabilitation program for concussion management in children and adolescents. Brain Inj 2017;31:1753-9.

13 Dobney DM, Grilli L, Beaulieu C, et al. Feasibility of early active rehabilitation for concussion recovery in youth: a randomized trial. Clin J Sport Med 2020;30:519-25.

14 Hunt AW, Agnihotri S, Sack L, et al. Mood-Related changes in children and adolescents with persistent concussion symptoms following a six-week active rehabilitation program. Brain Inj 2020;34:1068-73.

15 Chan C, Iverson GL, Purtzki J, et al. Safety of active rehabilitation for persistent symptoms after pediatric sport-related concussion: a randomized controlled trial. Arch Phys Med Rehabil 2018;99:242-9.
16 Chrisman SPD, Whitlock KB, Mendoza JA, et al. Pilot randomized controlled trial of an exercise program requiring minimal in-person visits for youth with persistent sport-related concussion. Front Neurol 2019;10:623.

17 Stewart TC, Gilliland J, Fraser DD. An epidemiologic profile of pediatric concussions: identifying urban and rural differences. $J$ Trauma Acute Care Surg 2014:76:736-42.

18 Graves JM, Mackelprang JL, Moore M, et al. Rural-Urban disparities in health care costs and health service utilization following pediatric mild traumatic brain injury. Health Serv Res 2019;54:337-45.

19 Graves JM, Moore M, Kehoe L, et al. Family hardship following youth concussion: beyond the medical bills. J Pediatr Nurs 2020;51:15-20.

20 Kho ME, Thabane L. Pilot and feasibility studies in rehabilitation: moving into the next decade. Physiother Can 2020;72:225-7.

21 Tickle-Degnen L. Nuts and bolts of conducting feasibility studies. Am J Occup Ther 2013;67:171-6.

22 Sady MD, Vaughan CG, Gioia GA. Psychometric characteristics of the postconcussion symptom inventory in children and adolescents. Arch Clin Neuropsychol 2014;29:348-63.

23 Roemmich JN, Barkley JE, Epstein LH, et al. Validity of PCERT and Omni walk/run ratings of perceived exertion. Med Sci Sports Exerc 2006;38:1014-9

24 Hunt AW, De Feo L, Macintyre J, et al. Development and feasibility of an evidence-informed self-management education program in pediatric concussion rehabilitation. BMC Health Serv Res 2016;16:400.

25 Orsmond GI, Cohn ES. The distinctive features of a feasibility study: objectives and guiding questions. OTJR 2015;35:169-77.

26 Rothwell PM. Factors that can affect the external validity of randomised controlled trials. PLoS Clin Trials 2006;1:e9.

27 Harris PA, Taylor R, Thielke R, et al. Research electronic data capture (REDCap)--a metadata-driven methodology and workflow process for providing translational research informatics support. J Biomed Inform 2009;42:377-81.

28 Parmanto B, Lewis, Jr. AN, Graham KM, et al. Development of the telehealth usability questionnaire (TUQ). Int J Telerehabil 2016;8:3-10.

29 Mah K, Hickling A, Reed N. Perceptions of mild traumatic brain injury in adults: a scoping review. Disabil Rehabil 2018;40:960-73.

30 Broadbent E, Wilkes C, Koschwanez H, et al. A systematic review and meta-analysis of the brief illness perception questionnaire. Psychol Health 2015;30:1361-85.

31 Law MC, McColl MA, Polatajko HJ. Canadian occupational performance measure. 5th edition. Ottawa: CAOT Publications ACE, 2014.

32 Attkisson CC, Zwick R. The client satisfaction questionnaire. psychometric properties and correlations with service utilization and psychotherapy outcome. Eval Program Plann 1982;5:233-7.

33 Chrisman SPD, Mendoza JA, Zhou C, et al. Pilot study of telehealth delivered rehabilitative exercise for youth with concussion: the mobile subthreshold exercise program (MSTEP). Front Pediatr 2021;9:645814

34 Hunt AW, Laupacis D, Kawaguchi E, et al. Key ingredients to an active rehabilitation programme post-concussion: perspectives of youth and parents. Brain Inj 2018;32:1534-40.

35 Thastum MM, Rask CU, Næss-Schmidt ET, et al. Novel interdisciplinary intervention, gain, vs. enhanced usual care to reduce high levels of post-concussion symptoms in adolescents and young adults 2-6 months post-injury: a randomised trial. EClinicalMedicine 2019;17:100214.

36 Ellis MJ, Russell K. The potential of telemedicine to improve pediatric concussion care in rural and remote communities in Canada. Front Neurol 2019;10:840.

37 Elbin RJ, Stephenson K, Lipinski D, et al. In-Person versus telehealth for concussion clinical care in adolescents: a pilot study of therapeutic alliance and patient satisfaction. J Head Trauma Rehabil 2021. doi:10.1097/HTR.0000000000000707. [Epub ahead of print: 26 Jul 2021]

38 Womble MN, Reynolds E, Kissinger-Knox A, et al. The emerging role of telehealth for concussion clinical care during the coronavirus (COVID-19) pandemic. J Head Trauma Rehabil 2021. doi:10.1097/HTR.0000000000000713. [Epub ahead of print: $26 \mathrm{Jul}$ 2021].

39 Mckinnon K, Hunt A, Knight K. Does screen time affect recovery from concussion in adolescents? Arch Dis Child 2021;106:720-2.

40 Macnow T, Curran T, Tolliday C, et al. Effect of screen time on recovery from concussion: a randomized clinical trial. JAMA Pediatr 2021;175:1124-31

41 Kontos AP, Eagle SR, Holland CL, et al. Effects of the COVID-19 pandemic on patients with concussion presenting to a specialty clinic. J Neurotrauma 2021;38:2918-22. 